http://dx.doi.org/10.32929/2446-8355.2021v30n2p190-203

\title{
ATRIBUTOS FÍSICOS DE UM LATOSSOLO SOB SISTEMAS DE USO E MANEJO NO MÉDIO VALE DO PARAÍBA PAULISTA
}

\section{Júlio César Ribeiro ${ }^{*}$, Julio Cesar Raposo de Almeida ${ }^{2}$, Ana Aparecida da Silva Almeida ${ }^{2}$, João Luiz Gadioli² ${ }^{2}$ Marcos Gervasio Pereira ${ }^{3}$}

\begin{abstract}
${ }^{1}$ Pós-Doutorando do Departamento de Solos. Universidade Federal Rural do Rio de Janeiro (UFRRJ), Rodovia BR 465, km 07, CEP: 23890-000, Seropédica, RJ, Brasil. *E-mail do autor correspondente: jcragronomo@gmail.com

2 Professor do Departamento de Ciências Agrárias. Universidade de Taubaté (UNITAU), Estrada Municipal Doutor José Luiz Cembranelli, n5000, CEP: 12081-010, Taubaté, SP, Brasil.

${ }^{3}$ Professor do Departamento de Solos. Universidade Federal Rural do Rio de Janeiro (UFRRJ), Rodovia BR 465, km 07, CEP: 23890-000, Seropédica, RJ, Brasil.
\end{abstract}

Recebido: 04/11/2021; Aceito: 13/12/2021

RESUMO: Os atributos físicos do solo são indicadores indispensáveis na avaliação de diferentes sistemas de uso e manejo do solo. Objetivou-se, nesse trabalho, avaliar o efeito dos sistemas de uso e manejo i) pupunha para produção de frutos e sementes, ii) pupunha para produção de palmito, e iii) pastagem de Urochloa decumbens em pousio, em profundidade sobre os atributos físicos de um Latossolo Vermelho-Amarelo localizado no médio Vale do Paraíba Paulista, SP, Brasil. Em cada sistema foi determinada a resistência do solo à penetração nas profundidades de 0,00-0,10, 0,10-0,20 e 0,20-0,40 m, nas quais foram coletadas amostras para a determinação do teor de matéria orgânica, densidade do solo e de partículas e umidade (conteúdo de água) no solo. A condutividade hidráulica, densidade de partículas, porosidade e volume de saturação foram determinadas por meio da coleta de amostras nas profundidades de 0,00-0,10 e 0,40-0,50 m. Verificou-se que não houve diferença para os atributos densidade de partículas, densidade do solo, porosidade total, resistência à penetração e matéria orgânica entre os sistemas de uso e manejo avaliados. Contudo, a condutividade hidráulica e o conteúdo de água (umidade) no solo foram maiores na área de pastagem de Urochloa decumbens em pousio. Os parâmetros densidade do solo, resistência à penetração e matéria orgânica apresentaram maiores valores em menor profundidade, enquanto a porosidade total, conteúdo de água (umidade) e condutividade hidráulica apontaram menores valores. A densidade de partículas e volume de saturação não foram influenciadas significativamente em profundidade.

Palavras-chave: Compactação do solo. Condutividade hidráulica. Qualidade física do solo. Urochloa decumbens. Bactris gasipaes Kunth.

\section{PHYSICAL ATTRIBUTES OF A LATOSOL UNDER USE AND MANAGEMENT SYSTEMS IN THE MIDDLE VALE DO PARAÍBA PAULISTA}

ABSTRACT: The physical attributes of the soil are indispensable indicators in the evaluation
of different land use and management systems. The objective of this work was to evaluate the
effect of use and management systems i) peach palm for fruit and seed production, ii) peach 
palm for palm heart production, and iii) fallow Urochloa decumbens pasture, in depth, on physical attributes of a Oxisol (Latossolo Vermelho-Amarelo) located in the middle Vale do Paraíba Paulista, SP, Brazil. In each system, the resistance of the soil to penetration was determined at depths of 0.00-0.10, 0.10-0.20 and 0.20-0.40 m, in which samples were collected to determine the content of organic matter, soil and particle density and moisture (water content) in the soil. Hydraulic conductivity, particle density, porosity and saturation volume were determined by collecting samples at depths of $0.00-0.10$ and $0.40-0.50 \mathrm{~m}$. It was found that there was no difference for the attributes particle density, soil density, total porosity, resistance to penetration and organic matter between the evaluated use and management systems. However, the hydraulic conductivity and water content (moisture) in the soil were higher in the fallow Urochloa decumbens pasture area. The parameters soil density, resistance to penetration and organic matter showed higher values at lower depth, while total porosity, water content (moisture) and hydraulic conductivity showed lower values. Particle density and saturation volume were not significantly influenced in depth.

Key words: Soil compaction. Hydraulic conductivity. Physical soil quality. Urochloa decumbens. Bactris gasipaes Kunth.

\section{INTRODUÇÃO}

O Vale do Paraíba Paulista está localizado entre as Serras da Mantiqueira e a do Mar, na região leste do estado de São Paulo, sendo caracterizado por grandes extensões de várzeas e "mares de morros" (EMPRESA PAULISTA DE PLANEJAMENTO METROPOLITANO S.A. - EMPLASA, 2013) com a presença de diversos tipos de solos, dentre os quais os Latossolos se destacam pela extensão de área que ocupam, e o grande potencial produtivo agropecuário que possibilitam. Os Latossolos geralmente apresentam-se fortemente intemperizados e suscetíveis aos processos erosivos, acarretando perdas de nutrientes e alterações na qualidade física se mal manejados, levando assim a busca por sistemas produtivos que visem a sua sustentabilidade (RIBEIRO et al., 2019; RIBEIRO et al., 2020).

A intensificação dos sistemas produtivos agropecuários tem ocasionado cada vez mais modificações nas propriedades físicas do solo, principalmente em decorrência das diferentes formas de uso e manejo adotados, em que não só os atributos do solo, assim como, o tipo de cultura utilizada podem intensificar o processo de degradação a médio e longo prazo (ASSIS et al., 2015; COSTA et al., 2015; TOIGO et al., 2015; TORRES et al., 2015). Desse modo, a implementação de sistemas que favoreçam a agregação do solo com o aporte de matéria orgânica, principalmente em solos que evidenciem sinais de degradação, são fundamentais para a melhoria de sua qualidade física (STEFANOSKI et al., 2013; ASSIS et al., 2015; COSTA et al., 2015; RESENDE et al., 2015; MASCARENHAS et al., 2017), visto que atributos como a densidade, porosidade e condutividade hidráulica são preservados reduzindo a compactação e promovendo, consequentemente, um melhor desenvolvimento das culturas. Tais atributos têm sido utilizados como forma de identificação de degradação e determinação da qualidade física do solo provocada pelos mais diversos tipos de uso e manejo (ASSIS et al., 2015; SILVA et al., 2015; NASCIMENTO et al., 2017). 
De encontro às necessidades do aporte de material orgânico ao solo, buscando promover melhorarias em sua qualidade física, o cultivo da pupunha (Bactris gasipaes Kunth) vem ganhando destaque. Sua boa adaptação às condições edafoclimáticas do local de estudo associado a sua versatilidade agroalimentícia para a produção de palmitos, frutos e sementes com elevado valor nutritivo, tem tornado a cultura uma opção para a diversificação e incremento na renda de propriedades rurais. A deposição sobre o solo de partes vegetativas como limbos e bainhas foliares ou de resíduos provenientes da colheita de palmitos contribui para o aporte de biomassa e, consequentemente, na melhoria da qualidade química e física do solo ao longo do tempo (ANEFALOS et al., 2007; RIBEIRO et al., 2020).

Grande parte das áreas agricultáveis do médio Vale do Paraíba Paulista, compostas por Latossolos localizados nas partes mais baixas do relevo, encontram-se em condições de suscetibilidade a erosão (PINTO et al., 2015; RIBEIRO et al., 2019), e estão em sua maioria ocupados por pastagens plantadas. Entretanto, a substituição da vegetação nativa por pastagens plantadas e utilizadas sob regimes extensivos de pastejo sem o preparo adequado do solo como a correção e adubação de manutenção, aliado a utilização de forrageiras com elevada necessidade de fertilidade, fazem com que ocorra um acelerado empobrecimento do solo pela ausência de reposição de nutrientes, perda de matéria orgânica, acidificação, mudanças na densidade, porosidade, resistência a penetração e condutividade hidráulica, levando ao intensivo processo de degradação química e física do solo ao longo do tempo (COSTA et al., 2015; RESENDE et al., 2015; MASCARENHAS et al., 2017). Dentre as principais espécies utilizadas para a formação de pastagens para a alimentação animal, a Urochloa decumbens tem se destacado, representando aproximadamente $80 \%$ das áreas cultivadas, particularmente em virtude a sua baixa exigência em fertilidade, alta produção de matéria seca, resistência a doenças e bom valor nutritivo (KLUTHCOUSKI et al., 2013).

Por apresentarem sistema radicular considerado agressivo devido sua alta capacidade de produção e renovação, as Urochloas são comparadas a equipamentos agrícolas descompactadores do solo, proporcionando a formação de canais subterrâneos, que auxiliam na melhoria da qualidade física do solo e consequentemente na infiltração e armazenamento de água (CECCON; MACHADO, 2008).

Diante desse contexto, o objetivo do trabalho foi avaliar o efeito de diferentes sistemas de uso e manejo com pupunha para produção de frutos e sementes; pupunha para produção de palmito e; pastagem de Urochloa decumbens em pousio, em profundidade sobre os atributos físicos de um Latossolo Vermelho-Amarelo localizado no médio Vale do Paraíba Paulista, SP, Brasil.

\section{MATERIAL E MÉTODOS}

O estudo foi realizado nos meses de junho/julho (estação seca/inverno) do ano de 2011 na Fazenda Piloto do Departamento de Ciências Agrárias da Universidade de Taubaté UNITAU, Taubaté-SP, sob as coordenadas $23^{\circ} 01^{\prime}$ de Latitude $\mathrm{S}$ e $45^{\circ} 30^{\prime}$ de Longitude W. O solo em questão foi classificado como Latossolo Vermelho-Amarelo. O clima local é do tipo Cwa, classificado segundo Köppen como temperado úmido com inverno seco e verão quente, 
estando a área situada a $565 \mathrm{~m}$ de altitude, com regime pluviométrico anual médio de 1.350 mm e temperatura média de $21,9^{\circ} \mathrm{C}$ (FOLHES; FISCH, 2006).

O delineamento experimental utilizado foi inteiramente casualizado, sendo os tratamentos: pastagem de Urochloa decumbens em pousio, pupunha para produção de palmito, e pupunha para produção de frutos e sementes (Figura 1A), divididos em quadrantes (Figura 1B).
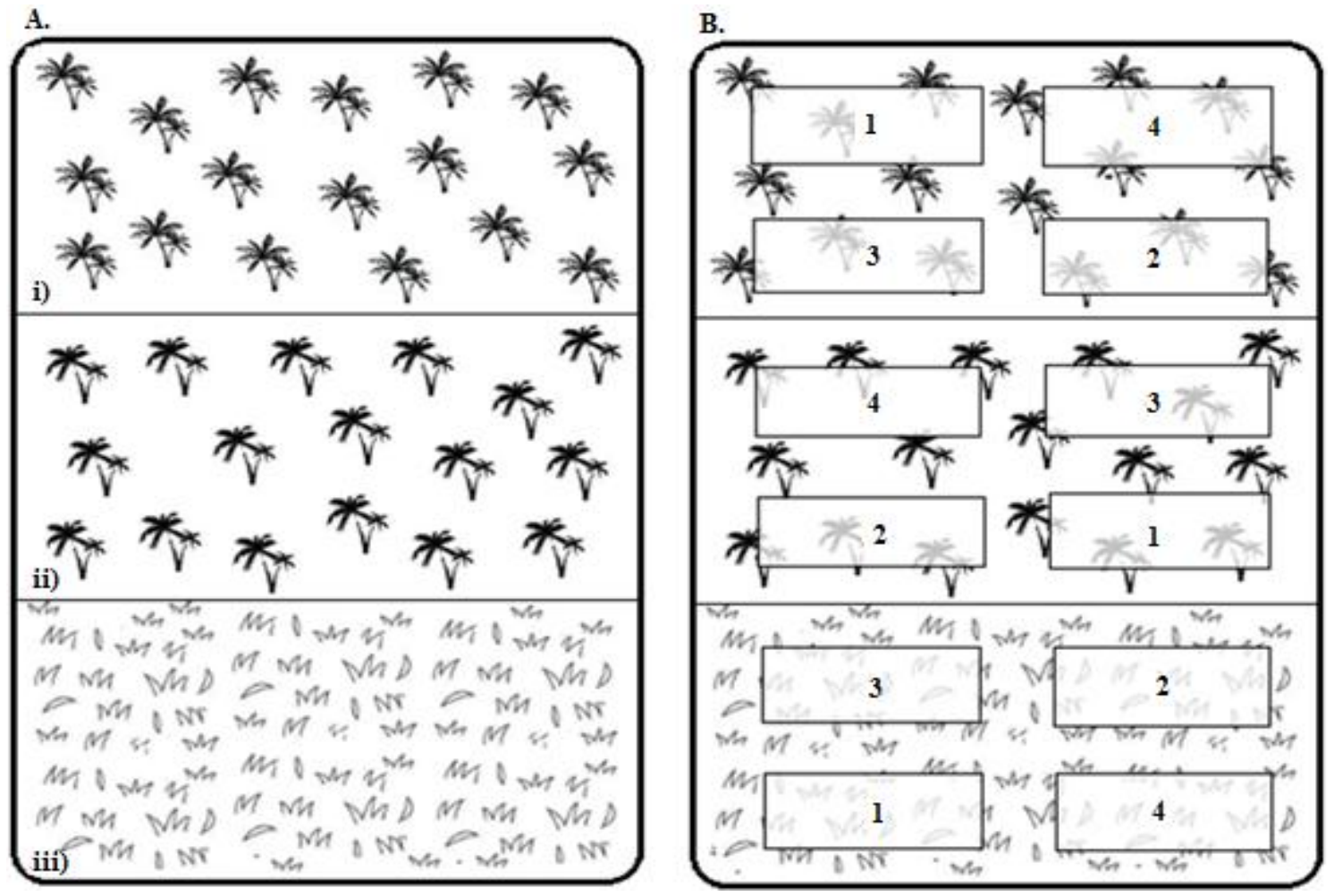

Figura 1. Croqui da área experimental para avaliação de propriedades físicas do solo em função de diferentes usos e manejos no médio Vale do Paraíba Paulista. Universidade de Taubaté UNITAU, Taubaté-SP. Sketch of the experimental area for evaluation of soil physical properties as a function of different uses and management in the middle Vale do Paraíba Paulista. Universidade de Taubaté - UNITAU, Taubaté-SP.

Fonte: Autoria própria. Own authorship.

O palmital foi implantado com espaçamento de 2 x $1 \mathrm{~m}$, no ano de 1998 sob uma área de Urochloa decumbens utilizada com pastagem extensiva, a qual foi arada e gradeada, sendo realizada a calagem e adubação de plantio nas covas.

$\mathrm{Na}$ área destinada à produção de palmitos foi realizada anualmente adubação de manutenção com $100 \mathrm{~kg} \mathrm{ha}^{-1}$ de sulfato de amônio e $40 \mathrm{~kg} \mathrm{ha}^{-1}$ de cloreto de potássio; e a cada três anos era realizada a adubação com $30 \mathrm{~kg} \mathrm{ha}^{-1}$ de super fosfato simples e, $2 \mathrm{~kg} \mathrm{ha}^{-1}$ de bórax. Essa mesma área era submetida anualmente a extração de palmito, sendo todos os resíduos depositados sobre o solo. Na área utilizada para a produção de frutos e sementes, a cada três anos era realizada a adubação com $2 \mathrm{~kg} \mathrm{ha}^{-1}$ de Bórax. A área de pastagem com Urochloa decumbens permaneceu em pousio desde a implantação do palmital, sem nenhum tipo de adubação mineral. Foi delimitada uma área de aproximadamente 0,5 ha para as avaliações. As áreas eram submetidas a roçadas frequentes, sendo a biomassa cortada, mantida no local. 
Nos quadrantes das áreas analisadas foram abertas trincheiras de 0,40 x 0,40 m de superfície x 0,50 $\mathrm{m}$ de profundidade para coleta de amostras de solo deformadas e indeformadas nas profundidades de 0,00-0,10, 0,10-0,20 e 0,20-0,40 m.

As amostras deformadas foram coletadas com trado sonda, secas ao ar, passadas por peneiras (malha de $2 \mathrm{~mm}$ ) e submetidas a oxidação via úmida para a determinação do teor de matéria orgânica do solo, segundo Raij et al. (2001). As amostras com estrutura preservada (indeformadas) foram coletadas usando um cilindro volumétrico de aço inoxidável com 2,98 cm de altura e 4,85 cm de diâmetro para a determinação da densidade e umidade (conteúdo de água) do solo de acordo com Donagemma et al. (2011).

Nas profundidades de 0,00-0,10 e 0,40-0,50 m, também foram coletadas amostras de solo com estrutura preservada utilizando-se o extrator de Uhland com anéis volumétricos de 5,29 $\mathrm{cm}$ de altura e 4,85 cm de diâmetro, para a determinação da condutividade hidráulica saturada, densidade de partículas, porosidade e volume de saturação segundo Donagemma et al. (2011). Na determinação da condutividade hidráulica, as amostras foram saturadas por $48 \mathrm{~h}$ em bandeja com água até dois terços da altura do anel e em seguida submetidas ao método do permeâmetro de carga constante, que consistiu em estabelecer uma carga hidráulica contínua com uma lâmina d'água de 2,0 a 4,0 cm sobre os anéis e posteriormente medir a vazão infiltrada, através da amostra.

No campo, em um raio de 2 metros da trincheira, onde as amostras foram coletadas, determinou-se a resistência do solo à penetração na profundidade de $0,00-0,10,0,10-0,20$ e 0,20-0,40 m, utilizando-se penetrômetro de impacto (modelo IAA/Planalsucar-Stolf), cujos resultados foram calculados de acordo com Stolf (1991). Para a conversão de $\mathrm{kgf} \mathrm{cm}^{-2} \mathrm{em} \mathrm{MPa,}$ multiplicou-se o resultado obtido pela constante 0,0981, conforme Beutler et al. (2001).

Os dados foram submetidos à análise de variância e, em caso de $\mathrm{F}$ significativo $(\rho \leq 0,05$ e $\rho \leq 0,01$ ), procedeu-se a comparação entre as médias pelo teste de Tukey ao nível de $5 \%$ e $1 \%$ de significância, utilizando o programa estatístico SAS.

\section{RESULTADOS E DISCUSSÃO}

Observou-se pela análise de variância que não ocorreu interação significativa para os atributos físicos do solo entre os sistemas de uso e manejo e as profundidades analisados $(\rho>0,05)$.

O sistema de uso e manejo do solo não influenciou significativamente $(\rho>0,05)$ a densidade de partículas, a densidade do solo e a porosidade total, indicando valores médios na ordem de 2,57 e 1,57 $\mathrm{Mg} \mathrm{m}^{-3}$, e 45,92\%, respectivamente (Tabela 1).

Contudo, a densidade média de partículas verificada no presente estudo $\left(2,57 \mathrm{Mg} \mathrm{m}^{-3}\right)$ (Tabela 1) é similar a observada por Giácomo et al. (2015) em Latossolo, sob diversas fitofisionomias do bioma cerrado (mata mesofítica, cerradão e cerrado sensu stricto), nos quais os autores constataram densidade média de partículas de $2,64 \mathrm{~kg} \mathrm{kg-}^{1}$. $\mathrm{O}$ valor de densidade (Dp) encontra-se próximo ao valor médio observado para os solos brasileiros $\left(2,65 \mathrm{Mg} \mathrm{m}^{-3}\right)$, 
sendo esse, um reflexo dos valores de massa específica dos principais constituintes das frações granulométricas dos solos brasileiros, quartzo na fração areia e caulinita na fração argila.

Tabela 1. Densidade de partículas, densidade do solo, porosidade total e umidade gravimétrica (conteúdo de água) de um Latossolo Vermelho-Amarelo em função dos diferentes sistemas de uso e manejo no médio Vale do Paraíba Paulista. Universidade de Taubaté - UNITAU, TaubatéSP. Particle density, soil density, total porosity and gravimetric moisture (water content) of an Oxisol (Latossolo Vermelho-Amarelo) as a function of different use and management systems in the middle Vale do Paraíba Paulista. Universidade de Taubaté - UNITAU, Taubaté-SP.

\begin{tabular}{lcccc}
\hline Sistema de manejo & $\begin{array}{c}\text { Densidade de } \\
\text { partículas }\left(\mathrm{Mg} \mathrm{m}^{-3}\right)\end{array}$ & $\begin{array}{c}\text { Densidade do } \\
\text { solo }\left(\mathrm{Mg} \mathrm{m}^{-3}\right)\end{array}$ & $\begin{array}{c}\text { Porosidade total } \\
(\%)\end{array}$ & $\begin{array}{c}\text { Umidade } \\
\text { gravimétrica }(\%)\end{array}$ \\
\hline Pupunha Frutos/Sementes & $2,55 \mathrm{a}$ & $1,59 \mathrm{a}$ & $46,85 \mathrm{a}$ & $14,68 \mathrm{~b}$ \\
Pupunha Palmito & $2,54 \mathrm{a}$ & $1,57 \mathrm{a}$ & $43,77 \mathrm{a}$ & $15,61 \mathrm{ab}$ \\
Pastagem & $2,63 \mathrm{a}$ & $1,55 \mathrm{a}$ & $47,13 \mathrm{a}$ & $16,20 \mathrm{a}$ \\
\hline Média & 2,57 & 1,57 & 45,92 & 15,5
\end{tabular}

Médias seguidas de letras iguais na coluna, não diferem entre si, pelo teste de Tukey, a 5\% de probabilidade. Means followed by equal letters in the column, do not differ by Tukey's test at $5 \%$ probability.

Fonte: Autoria própria. Own authorship.

O valor médio de densidade do solo $\left(1,57 \mathrm{Mg} \mathrm{m}^{-3}\right)$ encontrado nesse estudo (Tabela 1) é corroborado por Resende et al. (2015), que na avaliação de diferentes sistemas de manejo, verificaram em áreas de pastagem (Panicum maximum e Urochloa ruzizienses) com 15 anos em que anteriormente eram utilizadas para agricultura, e pastagem (Urochloa ruzizienses) com 30 anos de implantação, valores de densidade do solo na ordem de 1,59 e 1,61 $\mathrm{Mg} \mathrm{m}^{-3}$, respectivamente. Entretanto, o valor de porosidade total encontrada por esses autores (38 e $37 \%$ para pastagens com 15 e 30 anos de implantação, respectivamente), são inferiores aos verificados na área com pastagem de Urochloa decumbens em pousio (47,13\%) (Tabela 1). Valores similares aos observados, também foram constatados por Torres et al. (2015) na avaliação dos atributos físicos de um Latossolo submetido ao cultivo de diferentes plantas de cobertura por um período de 12 anos, no qual os autores verificaram em pastagem de Urochloa brizantha e em uma área sob pousio (vegetação espontânea composta basicamente por Poáceas), valores de densidade e porosidade do solo na ordem de 1,58 e 1,57 $\mathrm{Mg} \mathrm{m}^{-3} \mathrm{e}, 45,7 \mathrm{e}$ $45,8 \%$, respectivamente.

A umidade (conteúdo de água) do solo foi significativamente $(\rho \leq 0,05)$ influenciada pelo sistema de uso e manejo, apresentando a área de pastagem de Urochloa decumbens em pousio umidade estatisticamente maior $(16,20 \%)$, e a pupunha para a produção de frutos e sementes menor umidade $(14,68 \%)$. A área com pupunha para a produção de palmito não apresentou diferença significativa de umidade entre os sistemas avaliados (Tabela 1).

O maior valor do conteúdo de água (umidade) do solo verificado na área com Urochloa decumbens em pousio provavelmente se deve ao fato da mesma ter apresentado menores valores de densidade do solo e maior porosidade, o que favoreceu a maior retenção de água no solo nesse sistema. $\mathrm{O}$ maior volume total de poros está diretamente associado à densidade, e esses a estruturação do solo (MASCARENHAS et al., 2017; NASCIMENTO et al., 2017). 
Em profundidade, a densidade de partículas não diferiu estatisticamente entre os sistemas de uso e manejo $(\rho>0,05)$, apresentando a camada superficial $(0,00-0,10 \mathrm{~m})$ e subsuperficial $(0,40-0,50 \mathrm{~m})$ valores estatisticamente iguais entre si, na ordem de 2,55 e 2,60 $\mathrm{Mg} \mathrm{m}^{-3}$, respectivamente (Figura 2A), assim como verificado por Giácomo et al. (2015), que observaram densidade de partículas variando entre 2,55 a 2,73 $\mathrm{Mg} \mathrm{m}^{-3}$ até a profundidade de 0,40 m em diferentes fitofisionomias do bioma cerrado (mata mesofítica, cerradão e cerrado sensu stricto) sob Latossolo.

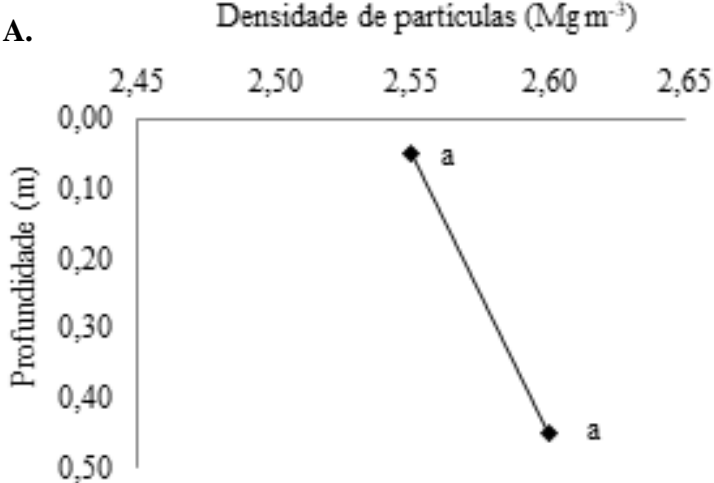

C.

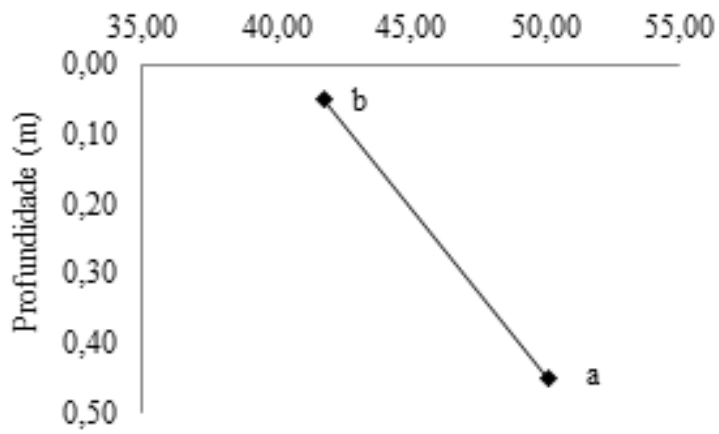

B. Densidade do solo $\left(\mathrm{Mg} \mathrm{m}^{-3}\right)$

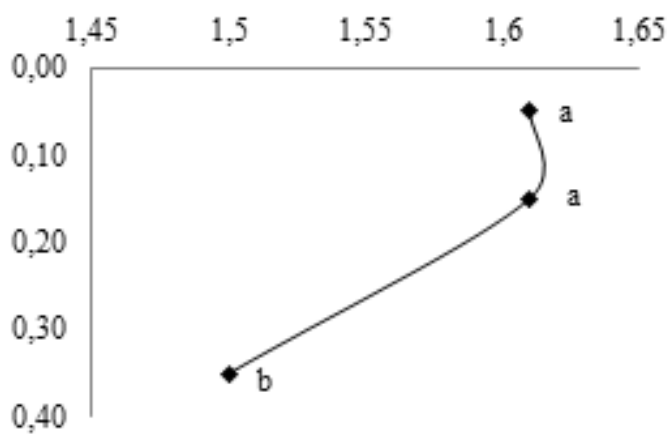

D. Umidade gravimétrica (\%)

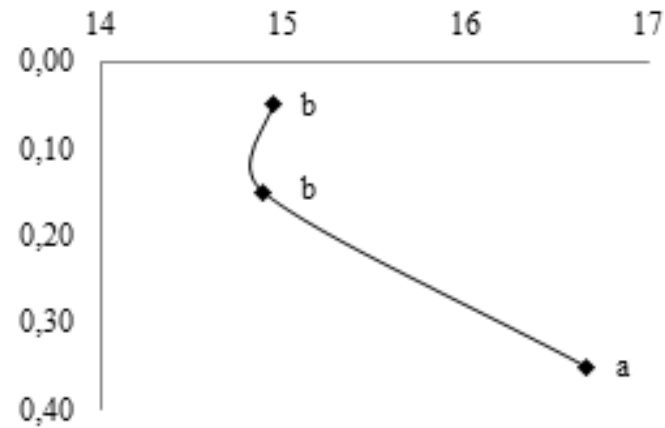

Médias seguidas por mesma letra em profundidade não diferem estatisticamente entre si pelo teste de Tukey a $5 \%$ de significância. Means followed by the same letter in depth do not differ statistically from each other by Tukey's test at 5\% significance

Figura 1. Densidade de partículas, densidade do solo, porosidade total e umidade gravimétrica (conteúdo de água) de um Latossolo Vermelho-Amarelo no médio Vale do Paraíba Paulista em função das profundidades analisadas. Universidade de Taubaté - UNITAU, Taubaté-SP. Particle density, bulk density, total porosity and gravimetric moisture (water content) of an Oxisol (Latossolo Vermelho-Amarelo) in the middle Vale do Paraíba Paulista as a function of the analyzed depths. Universidade de Taubaté - UNITAU, Taubaté-SP.

Fonte: Autoria própria. Own authorship.

Entretanto, a densidade, porosidade e a umidade (conteúdo de água) no solo foram significativamente influenciadas $(\rho \leq 0,01)$ em profundidade, apresentando para densidade do solo maiores valores nas camadas superficiais de 0,00-0,10 e 0,10-0,20 m, com menor porosidade total e consequentemente menor conteúdo de água (umidade). A camada mais profunda apresentou menor densidade do solo, maior porosidade, e em consequência maior teor de umidade (conteúdo de água) (Figura 2B, C e D). De acordo com Silva e Rosolem (2001), a densidade do solo verificada nas camadas superficiais $\left(1,61 \mathrm{Mg} \mathrm{m}^{-3}\right)$ está bem próxima, entretanto, um pouco acima do limite aceitável para o desenvolvimento adequado das culturas 
$\left(1,60 \mathrm{Mg} \mathrm{m}^{-3}\right)$, com exceção da camada mais profunda que apresentou densidade de $1,50 \mathrm{Mg}$ $\mathrm{m}^{-3}$. Resultados similares foram encontrados por Torres et al. (2015), que verificaram maior densidade e menor porosidade total nas camadas superficiais (até $0,20 \mathrm{~m}$ ), seguido de uma redução da densidade e aumento da porosidade total do solo na camada mais profunda $(0,30 \mathrm{~m})$ em um Latossolo cultivado com pastagem de Urochloa brizantha à 12 anos. Mascarenhas et al. (2017), constataram tendência de redução da densidade do solo em profundidade de avaliação $(0,00-0,20$ e $0,20-0,40 \mathrm{~m})$ em sistema de manejo extensivo com pastagem implantada a aproximadamente 15 anos.

Possivelmente a maior densidade do solo, menor porosidade e umidade (conteúdo de água) verificadas no presente estudo nas camadas superficiais, ocorreram em virtude do histórico da área, que era manejada sob pastejo extensivo antes da implantação dos sistemas, em que desde então (13 anos) não foi submetido a nenhum revolvimento, associado à falta de rotação de culturas por serem sistemas considerados perenes, o que segundo Costa et al. (2015) e Resende et al. (2015) causa compactação das camadas superficiais, afetando as propriedades físicas de solos antropizados.

A forma de uso e manejo não influenciou estatisticamente $(\rho>0,05)$ o volume de saturação do solo, apresentando valor médio de 43,85\% (Tabela 2).

Tabela 2. Volume de saturação, matéria orgânica do solo (MOS), resistência à penetração e condutividade hidráulica (K0) de um Latossolo Vermelho-Amarelo em função dos diferentes sistemas de uso e manejo no médio Vale do Paraíba Paulista. Universidade de Taubaté UNITAU, Taubaté-SP. Saturation volume, soil organic matter (MOS), penetration resistance and hydraulic conductivity (KO) of na Oxisol (Latossolo Vermelho-Amarelo) as a function of different use and management systems in the middle Vale do Paraíba Paulista. Universidade de Taubaté - UNITAU, Taubaté-SP.

\begin{tabular}{lcccc}
\hline Sistema de manejo & $\begin{array}{c}\text { Volume de } \\
\text { saturação }(\%)\end{array}$ & MOS $\left(\mathrm{g} \mathrm{kg}^{-1}\right)$ & Resistência $(\mathrm{MPa})$ & $\mathrm{K} 0\left(\mathrm{~cm} \mathrm{~h}^{-1}\right)$ \\
\hline Pupunha Frutos/Sementes & $44,28 \mathrm{a}$ & $17,33 \mathrm{a}$ & $8,21 \mathrm{a}$ & $799,00 \mathrm{~b}$ \\
Pupunha Palmito & $42,42 \mathrm{a}$ & $19,50 \mathrm{a}$ & $7,87 \mathrm{a}$ & $207,00 \mathrm{~b}$ \\
Pastagem & $44,86 \mathrm{a}$ & $20,83 \mathrm{a}$ & $5,45 \mathrm{a}$ & $1663,60 \mathrm{a}$ \\
\hline Média & 43,85 & 19,22 & 7,18 & 889,8 \\
\hline
\end{tabular}

Médias seguidas de letras iguais na coluna, não diferem entre si, pelo teste de Tukey, a 5\% de probabilidade. Means followed by equal letters in the column, do not differ by Tukey's test at 5\% probability.

Fonte: Autoria própria. Own authorship.

O volume de saturação do solo, também não foi influenciado $(\rho>0,05)$ em profundidade (Figura 3A). Apesar de não ser verificada diferença estatística entre as profundidades avaliadas, observou-se uma variação de $2,2 \%$ do volume de saturação em profundidade, provavelmente em função da menor densidade, maior porosidade e umidade (conteúdo de água) do solo constatada nessa situação. 
A. Volume de saturação (\%)

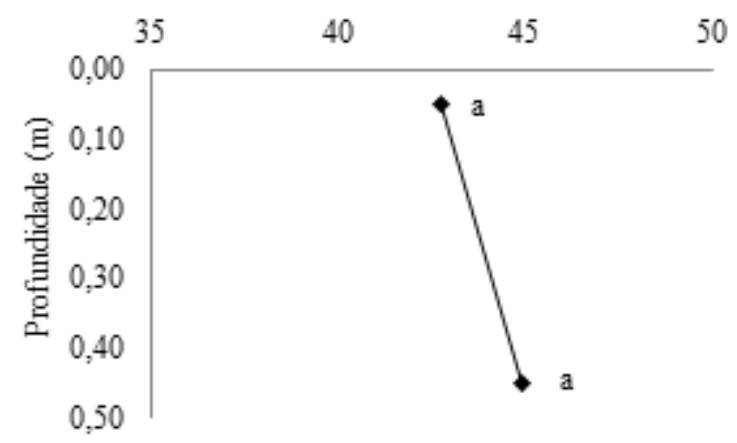

C.

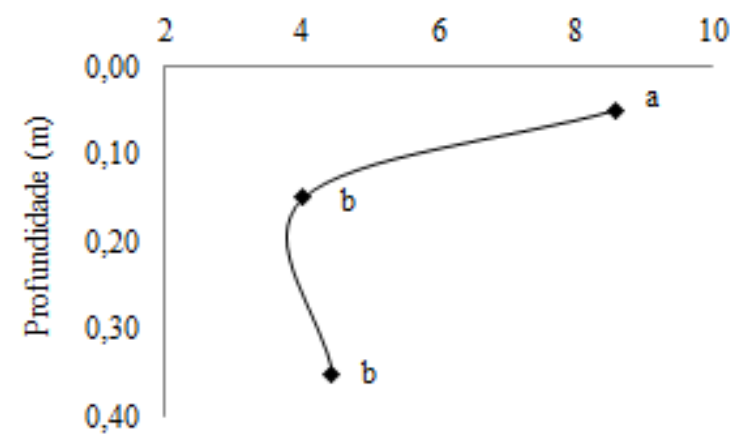

B. Matéria orgânica do solo $\left(\mathrm{g} \mathrm{kg}^{\mathrm{i}}\right)$

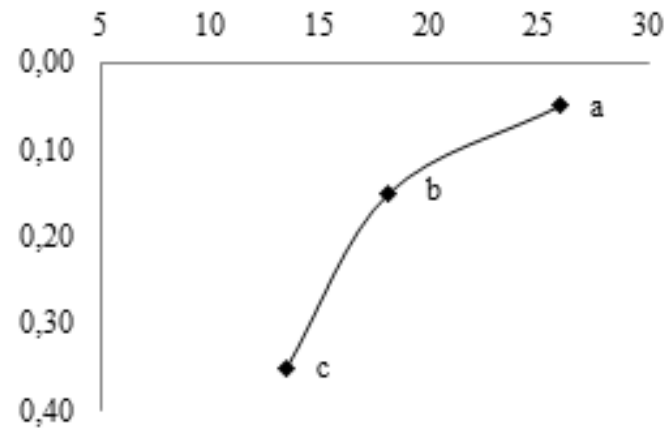

D. Condutividade hidráulica $\left(\mathrm{cm} \mathrm{h}^{-3}\right)$

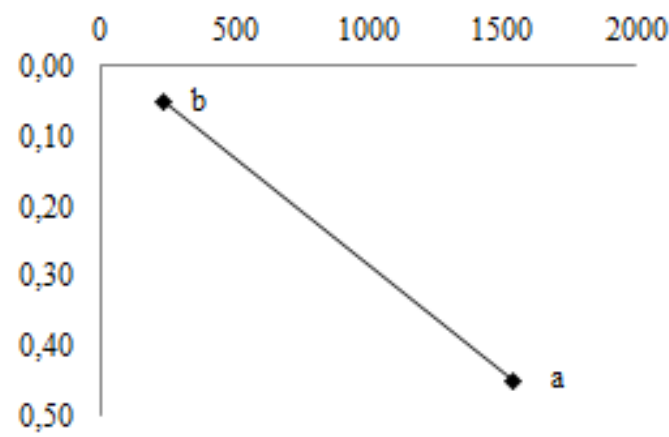

Médias seguidas por mesma letra em profundidade não diferem estatisticamente entre si pelo teste de Tukey a 5\% de significância. Means followed by the same letter in depth do not differ statistically from each other by Tukey's test at 5\% significance.

Figura 3. Volume de saturação, matéria orgânica do solo, resistência à penetração e condutividade hidráulica de um Latossolo Vermelho-Amarelo no médio Vale do Paraíba Paulista em função das profundidades analisadas. Universidade de Taubaté - UNITAU, Taubaté-SP. Saturation volume, soil organic matter, penetration resistance and hydraulic conductivity of an Oxisol (Latossolo Vermelho-Amarelo) in the middle Vale do Paraíba Paulista as a function of the analyzed depths. Universidade de Taubaté - UNITAU, TaubatéSP.

Fonte: Autoria própria. Own authorship.

O teor de matéria orgânica do solo não foi estatisticamente influenciado $(\rho>0,05)$ pela forma de uso e manejo, apresentando valor médio de 19,22 $\mathrm{g} \mathrm{kg}^{-1}$ (Tabela 2). Apesar disso, a área com pastagem de Urochloa decumbens em pousio apresentou variação de $20,2 \%$ de matéria orgânica quando comparada a área com pupunha para a produção de frutos e sementes. Contudo, em profundidade foram observadas diferenças significativas $(\rho \leq 0,01)$, apresentando a profundidade de 00-0,10 m valor estatisticamente superior $\left(26,0 \mathrm{~g} \mathrm{~kg}^{-1}\right)$ de matéria orgânica em comparação as profundidades de 0,10-0,20 e 0,20-0,40 m $\left(18,17\right.$ e $13,5 \mathrm{~g} \mathrm{~kg}^{-1}$, respectivamente) (Figura 3B).

Essa mesma tendência de redução no teor de matéria orgânica em profundidade foi observada por Lisboa et al. (2016) na avaliação de indicadores da qualidade física de um Latossolo sob áreas de pastagens com predomino de Urochloa decumbens, constatando teores de 26,3 e 23,4 $\mathrm{g} \mathrm{kg}^{-1}$ nas profundidades de 0,00-0,10 e 0,10-0,20 m, respectivamente. Os mesmos autores verificaram que o maior teor de matéria orgânica na camada superficial não 
proporcionou a redução da densidade e maior porosidade do solo, corroborando com resultados obtidos no presente estudo.

A resistência do solo à penetração não foi influenciada estatisticamente $(\rho>0,05)$ pelo sistema de uso e manejo do solo, apresentando resistência média de 7,18 MPa (Tabela 2). Assim como constatado por Costa et al. (2012), observou-se que à medida que os sistemas proporcionaram uma maior retenção de água no solo, a resistência do solo à penetração foi reduzida (mesmo esse atributo não indicando diferença estatística), apresentando a área com pupunha para a produção de frutos e sementes maior resistência do solo à penetração e menor conteúdo de água (umidade), seguida da área com pupunha para produção de palmito, e área com pastagem de Urochloa decumbens em pousio, com valores de 8,21, 7,87 e 5,45 MPa, respectivamente. Vale ressaltar, que em todos os sistemas estudados, os valores de resistência à penetração do solo podem ser classificados de acordo Ditzler et al. (2017) como muito alto ( $\mathrm{RP}>4,0 \mathrm{MPa}$ ), sendo superiores ao considerado limitante para o crescimento e desenvolvimento do sistema radicular de plantas perenes que é de $3 \mathrm{MPa}$ (BEUTLER et al., 2001). Contudo, Costa et al. (2012) avaliando o efeito do pastejo sob a qualidade física do solo e seu impacto na produção de forragem e raízes de Panicum maximum, observaram valores máximos de resistência do solo à penetração na ordem de $7 \mathrm{MPa}$, o que segundo os autores foi associado ao menor teor de umidade (conteúdo de água) no solo. Tais características influenciaram no crescimento e produção de raízes, o que reduziu a capacidade de absorção e consequentemente produção de biomassa das plantas.

Em profundidade, foram observadas diferenças significativas $(\rho \leq 0,01)$, apresentando a camada superficial $(0,00-0,10 \mathrm{~m})$ maior resistência à penetração $(8,56 \mathrm{MPa})$ quando comparada as camadas mais profundas $(0,10-0,20$ e 0,20-0,40 m) com menor resistência (4,02 e 4,45 MPa, respectivamente), não diferindo significativamente entre si (Figura 3C). Essa mesma tendência na redução da resistência à penetração do solo em profundidade foi verificada por Costa et al. (2015), em sistemas que apresentaram menor densidade, maior porosidade total e maior conteúdo de água (umidade) nas camadas mais profundas. Contudo, esses autores observaram valores na ordem de 2,52 e 2,50 MPa nas camadas de 0,00-0,10 e 0,20-0,40 m, respectivamente, dentre os diversos sistemas avaliados, valores os quais são inferiores aos verificados nesse estudo.

Os maiores valores de resistência à penetração do solo verificado podem estar associados ao manejo da área antes de serem implantados os sistemas, visto que a mesma era utilizada com pastagem extensiva, podendo a grande pressão exercida sobre o solo pelo pisoteio animal ter influenciado nesse atributo físico. Segundo Lopes et al. (2009), as camadas superficiais do solo podem, em decorrência do intenso pisoteio animal, serem submetidas à pressão superiores à utilização de máquinas agrícolas. Aliado a isso, a ausência de revolvimento do solo, associado ainda, a falta de rotação de cultura por serem sistemas perenes, tanto na área com pupunha quanto na área com Urochloa decumbens, desde a implantação dos sistemas há 13 anos, podem ter contribuído para o aumento da resistência a penetração na camada superficial, causando sua compactação, o que de acordo com Costa et al. (2015) é ocorrente em sistemas que não praticam essas técnicas. 
A condutividade hidráulica do solo foi estatisticamente $(\rho \leq 0,01)$ influenciada pelo sistema de uso e manejo (Tabela 2). A mesma pode ser afetada por parâmetros como densidade, porosidade e resistência do solo à penetração. Apesar da elevada resistência do solo à penetração verificada em ambos os sistemas avaliados, as plantas de Urochloa decumbens com ausência de pastejo por um período de 13 anos proporcionaram maior $\left(1663,60 \mathrm{~cm} \mathrm{~h}^{-1}\right)$ condutividade hidráulica no solo em relação à área com pupunha para produção de frutos e sementes, e a área com pupunha para a produção de palmitos, as quais não diferiam estatisticamente entre si.

Estudando a influência dos atributos físicos do solo sobre o escoamento superficial, Silva et al. (2015) verificaram maior taxa de infiltração em áreas de campo nativo pastejado (CNP), em relação aos sistemas de integração lavoura-pecuária (ILP) e lavoura-pecuária-floresta (ILPF), padrão justificado pelos autores em função a menor densidade do solo e a maior porosidade total, aliado ainda, a quantidade e qualidade de matéria orgânica aportado ao solo. Mesmo não apresentando diferença estatística entre os sistemas de manejo, a área com pastagem de Urochloa decumbens em pousio proporcionou maior teor de matéria orgânica, porosidade total, menor densidade e resistência do solo à penetração, podendo possivelmente ter contribuído para a maior condutividade hidráulica verificada nesse sistema.

Em profundidade, a condutividade hidráulica foi influenciada significativamente ( $\rho \leq 0,01)$, apresentando menor valor na camada superficial $(0,00-0,10 \mathrm{~m})$, seguido de maior valor na camada mais profunda do solo $(0,40-0,50 \mathrm{~m})$ (Figura 3D). A tendência do aumento dos valores de condutividade hidráulica em profundidade é corroborada por Silva et al. (2015), que também constataram resultado similar em diferentes sistemas de uso e manejo do solo (CNP, ILP e ILFP), demonstrando, como observado nesse estudo, maior densidade e menor porosidade na camada superficial do solo, seguido de uma menor densidade e consequentemente maior porosidade na camada mais profunda.

\section{CONCLUSÃO}

Não foi verificada diferença entre os sistemas de uso e manejo com pupunha para produção de frutos e sementes; pupunha para produção de palmito e; pastagem de Urochloa decumbens em pousio para os atributos densidade de partículas, densidade do solo, porosidade total, resistência do solo à penetração e matéria orgânica.

$\mathrm{Na}$ área de pastagem com Urochloa decumbens em pousio foram quantificados os maiores valores de umidade (conteúdo de água) e condutividade hidráulica do solo dentre os atributos analisados.

Os parâmetros densidade do solo, resistência à penetração e matéria orgânica apresentaram maiores valores em menor profundidade, enquanto a porosidade total, conteúdo de água (umidade) e condutividade hidráulica apontaram menores valores. A densidade de partículas e volume de saturação não foram influenciadas significativamente em profundidade.

O maior teor de matéria orgânica verificado na camada superficial $(0,00-0,10 \mathrm{~m})$ não foi suficiente para proporcionar redução nos valores de densidade do solo, maior porosidade e umidade (conteúdo de água), e consequentemente menor resistência do solo à penetração. 


\section{REFERÊNCIAS BIBLIOGRÁFICAS}

ANEFALOS, L. C.; MODOLO, V. A.; TUCCI, M. L. S. Expansão do cultivo da pupunheira no Vale do Ribeira, Estado de São Paulo, 2002-2006. Informações Econômicas, São Paulo, v. 37, n. 10, p.37-43, 2007.

ASSIS, P. C. R.; STONE, L. F.; MEDEIROS, J. C.; MADARI, B. E.; OLIVEIRA, J. M.; WRUCK, F. J. Atributos físicos do solo em sistemas de integração lavoura-pecuária-floresta. Revista Brasileira de Engenharia Agrícola e Ambiental, Campina Grande, v. 19, n. 4, p.309316, 2015. Disponível em: https://doi.org/10.1590/1807-1929/agriambi.v19n4p309-316. Acesso em: 09 dez. 2020.

BEUTLER, A. N.; SILVA, N. L. N.; CURI, N.; FERREIRA, M. M.; CRUZ, J. N.; PEREIRA FILHO, I. A. Resistência a penetração e permeabilidade de Latossolo Vermelho Distrófico típico sob sistemas de manejo na região dos cerrados. Revista Brasileira de Ciência do Solo, Viçosa, v. 25, n. 1 p.167-177, 2001. Disponível em: http://dx.doi.org/10.1590/S010006832001000100018. Acesso em: 09 dez. 2020

CECCON, G.; MACHADO, L. A. Z. Braquiária pode substituir "grade" do plantio direto no cerrado. In: Agrosoft Brasil. CECON, G.; ZAGO, L. A. Brasília. Embrapa Agropecuária Oeste. 2008. p.1. Disponível em: https://www.infoteca.cnptia.embrapa.br/infoteca/ handle/doc/242857. Acesso em: 09 dez. 2020.

COSTA, M. A. T.; TORMENA, C. A.; LUGÃO, S. M. B.; FIDALSKI, J.; NASCIMENTO, W. G.; MEDEIROS, F. M. Resistência do solo à penetração e produção de raízes e de forragem em diferentes níveis de intensificação do pastejo. Revista Brasileira de Ciência do Solo, Viçosa, v. 36, n. 2, p.993-1004, 2012. Disponível em: https://doi.org/10.1590/S010006832012000300029. Acesso em: 09 dez. 2020.

COSTA, N. R.; ANDREOTTI, M.; LOPES, K. S. M.; YOKOBATAKE, K. L.; FERREIRA, J. P.; PARIZ, C. M.; BONINI, C. S. B.; LONGHINI, V. Z. Atributos do solo e acúmulo de carbono na integração lavoura-pecuária em sistema plantio direto. Revista Brasileira de Ciência do solo, Viçosa, v. 30, n. 3, p.852-863, 2015. Disponível em: https://doi.org/10.1590/ 01000683rbcs20140269. Acesso em: 09 dez. 2020.

DITZLER, C.; SCHEFFE, K.; MONGER, H .C. Soil survey manual. Soil science division staff. USDA Handbook 18. Government printing office, Washington, D. C. 2017. Disponível em: https://www.nrcs.usda.gov/wps/portal/nrcs/detailfull/soils/ref/?cid=nrcs142p2_054262. 01. Acesso em: 09 dez. 2011.

DONAGEMMA, G. K.; CAMPOS, D. B.; CALDERANO, S. B.; TEIXEIRA, W. G.; VIANA, J. M. Manual de métodos de análise do solo. Rio de Janeiro: Empresa Brasileira de Pesquisa Agropecuária - Embrapa. Centro Nacional de Pesquisa de Solos., 2011. 230 p. Disponível em: https://www.infoteca.cnptia.embrapa.br/infoteca/handle/doc/990374. Acesso em: 09 dez. 2011.

EMPRESA PAULISTA DE PLANEJAMENTO METROPOLITANO SA - EMPLASA. Governo do Estado de São Paulo. Secretaria de Desenvolvimento Metropolitano. Região Metropolitana do Vale do Paraíba e Litoral Norte, 2013. 132 p. 
FOLHES, M. T.; FISCH, G. Caracterização climática e estudo de tendências nas séries temporais de temperatura do ar e precipitação em Taubaté - SP. Revista Ambiente e Água, Taubaté, v. 1, n. 1, p.61-71, 2006. Disponível em: https://www.redalyc.org/pdf/928/92810108.pdf. Acesso em: 09 dez. 2020.

GIÁCOMO, R. G. R.; PEREIRA, M. G.; GUARESCHI, R. F.; MACHADO, D. L. Atributos químicos e físicos do solo, estoque de carbono e nitrogênio e frações húmicas em diferentes formações vegetais. Ciência Florestal, Santa Maria, v. 25, n. 3, p.617-631, 2015. Disponível em: https://doi.org/10.5902/1980509819613. Acesso em: 09 dez. 2020.

KLUTHCOUSKI, J; CORDEIRO, L, A, M; CECCON, G; OLIVEIRA, P. Braquiária na agropecuária brasileira: uma história de sucesso. In: Consórcio milho-braquiária. CECCON, G. Brasília: Embrapa Agropecuária Oeste 2013. cap 1., p. 17-26.

LISBOA, F. M.; DONAGEMA, G. K.; BURAK, D. L.; PASSOS, R. R.; MENDONÇA, E. S. Indicadores de qualidade de Latossolo relacionados à degradação de pastagens. Pesquisa Agropecuária Brasileira, Brasília, v. 51, n. 9, p.1184-1193, 2016. Disponível em: https://doi.org/10.1590/S0100-204X2016000900018

LOPES, M. L. T.; CARVALHO, P. C. F; ANGHINONI, I.; SANTOS, D.T.; AGUINAGA, A. A. Q.; FLORES, J. P. C.; MORAES, A. Sistema de integração lavoura-pecuária: Efeito do manejo da altura em pastagem de aveia preta, azevém anual sobre o rendimento da cultura da soja. Ciência Rural, Santa Maria, v. 39, n. 5, p.1499-1506, 2009. Disponível em: https://doi.org/10.1590/S0103-84782009005000096. Acesso em: 09 dez 2020.

MASCARENHAS, A. R. P.; SCCOTI, M. S. V.; MELO, R. R.; CORRÊA, F. L. O.; SOUZA, E. F. M.; ANDRADE, R. A.; BERGAMIN, A. C; MULLER, M. W. Atributos físicos e estoques de carbono do solo sob diferentes usos da terra em Rondônia, Amazônia Sul-Ocidental. Revista Pesquisa Florestal Brasileira, [s. l.], v. 37, n. 89, p.19-27, 2017. Disponível em: https://doi.org/10.4336/2017.pfb.37.89.1295. Acesso em: 09 dez 2020.

NASCIMENTO, V. N.; ALMEIDA, G. L. P.; BATISTA, P. H. D.; COUTINHO, A. S. Atributos físicos do Neossolo Regolítico Distrófico sob pastagem submetido à colheita mecanizada da forragem e pastejo animal. Boletim de Indústria Animal, Nova Odessa, v. 74, n. 3, p. 169-175, 2017. Disponível em: https://doi.org/10.17523/bia.v74n3p169. Acesso em: 09 dez 2020.

PINTO, C. T.; OLIVEIRA, P. V. C.; PONZONI, F. G. CASTRO, R. M. Identificação de áreas susceptíveis a processos erosivos na região do Vale do Paraíba. In: SIMPÓSIO BRASILEIRO DE SENSORIAMENTO REMOTO, 22,2015, João Pessoa-PB. Anais [...] João Pessoa: Instituto Nacional de Pesquisas Espaciais - INPE, 2015. Disponível em: http://marte2.sid.inpe.br/col/sid.inpe.br/marte2/2015/06.15.13.59.43/doc/p0021.pdf. Acesso em: 09 dez. 2020.

RAIJ, B. V.; ANDRADE, J. C.; CANTARELLA, H.; QUAGGIO, J. A. Análise química para avaliação da fertilidade de solos tropicais. Campinas: Instituto Agronômico, 2001. 285 p. Disponível em: http://www.iac.agricultura.sp.gov.br/publicacoes/arquivos/ Raij_et_al_2001_ Metod_Anal_IAC.pdf. Acesso em: 09 dez. 2011. 
RESENDE, T. M.; ROSOLEN, V.; BERNOUR, M.; BRITO, J. L. S.; BORGES, E. N.; ALMEIDA, P. F. Atributos físicos e carbono orgânico em solo sob cerrado convertido para pastagem e sistema misto. Revista Sociedade e Natureza, Uberlândia, v. 27, n. 3, p.501-514, 2015. Disponível em: https://doi.org/10.1590/1982-451320150310. Acesso em: 09 dez. 2020.

RIBEIRO, J. C.; SILVA ALMEIDA, A. A.; ALMEIDA, J. C. R.; GADIOLI, J. L.; PEREIRA, M. G. Chemical properties of an Oxisol affected by different land use and soil management systems. Ambiente e Agua-An Interdisciplinary Journal of Applied Science, [s. l.], v. 15, n. 7, p.1-10, 2020. Disponível em: http://dx.doi.org/10.4136/ambi-agua.2575. Acesso em: 27 mar. 2021.

RIBEIRO, J. C.; ANJOS, L. H. C.; PEREIRA, M. G. Aptidão e capacidade de uso das terras do Vale do Paraíba Paulista para o cultivo de Tectona grandis L. Agrarian, Dourados, v. 12, n. 44, p.182-195, 2019. Disponível em: https://doi.org/10.30612/agrarian.v12i44.8944. Acesso em: 09 dez 2020.

SILVA, A. H.; FAVARETTO, N.; CAVALIERI, K. M. V.; DIECKOW, J.; VEZZANI, F. M.; PARRON, L. M.; CHEROBIM, V. F.; MARIOTI, J.; FERRARI-NETO, H. Atributos físicos do solo e escoamento superficial como indicadores de serviços ambientais. In: PARRON, L. M.; GARCIA, J. R.; OLIVEIRA, E. B.; BROW, G. G.; PRADO, R. B. Serviços ambientais em sistemas agrícolas e florestais do bioma Mata Atlântica. Brasília: Empresa Brasileira de Pesquisa Agropecuária - Embrapa Florestas, 2015. Disponível em: https://www.alice.cnptia.embrapa.br/handle/doc/1024321. Acesso em: 09 dez. 2020.

SILVA, R. H.; ROSOLEM, C. A. Crescimento radicular de espécies utilizadas como cobertura decorrente da compactação do solo. Revista Brasileira de Ciência do Solo, Viçosa, v. 25, n. 2, p.53-60, 2001. Disponível em: https://doi.org/10.1590/S0100-06832001000200001. Acesso em: 09 dez. 2020.

STEFANOSKI, D. C.; SANTOS, G.; MARCHÃO, R. L.; PETTER, F. A.; PACHECO, L. P. Uso e manejo do solo e seus impactos sobre a qualidade física. Revista Brasileira de Engenharia Agrícola e Ambiental, Campina Grande, v. 17, n. 12, p.1301-1309, 2013. Disponível em: https://doi.org/10.1590/S1415-43662013001200008. Acesso em: 09 dez. 2020.

STOLF, R. Teoria e teste experimental de fórmulas de transformação dos dados de penetrômetro de impacto em resistência do solo. Revista Brasileira de Ciência do Solo, Viçosa, v. 15, n. 2, p.29-35, 1991. Acesso em: 09 dez 2020.

TOIGO, S.; BRAIDA, J. A.; POSSETI, J. C.; BRANDELERO, E. M.; BAESSO, M. M. Atributos físicos de um Nitossolo Vermelho cultivado com trigo em sistema de plantio direto, submetido à compactação e escarificação. Revista Engenharia na Agricultura, [s. l.], v. 23, n. 1, p.19-28, 2015. Disponível em: https://doi.org/10.13083/1414-3984/reveng.v23n1p19-28. Acesso em: 09 dez. 2020.

TORRES, J. R.; PEREIRA, M. G.; ASSIS, R. L.; SOUZA, Z. M. Atributos físicos de um Latossolo Vermelho cultivado com plantas de cobertura, em semeadura direta. Revista Brasileira de Ciência do Solo, Viçosa, v. 39, n. 2, p.426-437, 2015. Disponível em: https://doi.org/10.1590/01000683rbcs20140597. Acesso em: 09 dez. 2020. 